\title{
Genotypic stabilization of agronomic traits in Panicum maximum (Jacq.) hybrids
}

\author{
Thiago Gomes dos Santos Braz', Dilermando Miranda da Fonseca², Liana Jank ${ }^{3}$, Cosme \\ Damião Cruz ${ }^{4}$, Janaina Azevedo Martuscello ${ }^{5}$
}

\author{
${ }^{1}$ Universidade Federal dos Vales do Jequitinhonha e Mucuri, Departamento de Zootecnia, Diamantina, MG, Brasil \\ 2 Universidade Federal de Viçosa, Departamento de Zootecnia, Viçosa, MG, Brasil. \\ ${ }^{3}$ Embrapa Gado de Corte, Campo Grande, MS, Brasil. \\ ${ }^{4}$ Universidade Federal de Viçosa, Departamento de Biologia Geral, Viçosa, MG, Brasil. \\ ${ }^{5}$ Universidade Federal de São João del-Rei, Departamento de Zootecnia, São João del-Rei, MG, Brasil.
}

\begin{abstract}
The objective of this study was to evaluate the genotypic stability of agronomic traits in hybrids of Panicum maximum. Hybrids originating from the crosses between two sexual parents and cultivars Mombasa and Tanzania were evaluated in an incomplete-block design. Evaluated traits were total dry matter, leaf dry matter, stem dry matter, percentage of leaves, and leaf:stem ratio. These traits were evaluated in six harvests. Overall, higher repeatability was observed for the traits total dry matter and leaf dry matter, especially when harvests 4,5 , and 6 , occurring in spring and summer, were evaluated. The leaf dry matter was the trait that provided the greatest repeatability and determination. The repeatability of stem dry matter, percentage of leaves, and leaf:stem ratio had a low magnitude, even when the coefficient was estimated based on the harvests of better stabilization for the other variables. The hybrids achieved genotypic stabilization in the harvests made in the second rainy season. Harvests made in the rainy season provide greater repeatability and determination, and the inclusion of the dry-season harvest is detrimental to the process of selection of low-repeatability traits such as percentage of leaves.
\end{abstract}

Key Words: coefficient of determination, forage, repeated measures, selection efficiency

\section{Introduction}

In recent years, Brazil has become the greatest exporter of beef, holding the largest commercial herd in the world. This great advance is a result of the operation of several lines of research, among which is the genetic breeding of forage plants, which has received increased attention because of the recognized importance of diversifying pastures. Nevertheless, the number of available cultivars of tropical forages is still low, and, of these, a small share results from crossing programs performed in Brazil (Valle et al., 2009).

Diversification through the development of more adapted and competitive forages is essential so as to mitigate the problems caused by the practice of monoculture. In this regard, the Panicum maximum Jacq. species is an excellent option for the diversification and intensification of Brazilian pastures. This forage is well diffused among livestock farmers, and is considered one of the most

Received February 10, 2015 and accepted August 9, 2015.

Corresponding author: thiagogsbz@hotmail.com

http://dx.doi.org/10.1590/S1806-92902015001100001

Copyright (C) 2015 Sociedade Brasileira de Zootecnia. This is an Open Access article distributed under the terms of the Creative Commons Attribution License (http://creativecommons.org/licenses/by/4.0/), which permits unrestricted use, distribution, and reproduction in any medium, provided the original work is properly cited. productive and competitive in the Brazilian livestock scenario (Jank et al., 2008; Jank et al., 2011).

To obtain the estimate of the superiority of perennial plants, successive measurements are often used in predetermined time intervals; thus, the genotypes are evaluated in regular intervals, aiming at the same vegetative stage, and each harvest can be considered a replicate in time. The coefficient of repeatability, defined statistically as the correlation between measures in a same individual, whose evaluations have been repeated in time or space, expresses the fractions of the total variance that are explained by genetic causes mistaken for the permanent effect of environment and which are attributed to temporary variations (Cruz et al., 2004). Because experiments with the breeding of forages (perennial plants) are extremely costly as they involve evaluation with animals, in successive harvests, large areas and in several locations, it is essential to have reliable identification of superior individuals through repeated measures.

According to Pereira et al. (2002), during the young stage, only part of the genes responsible for the traits of interest is expressing itself, whereas at adult age all the plant potential is manifested, resulting in marked changes in the phenotype. In this situation, the evaluation of individuals through repeated measures in different stages of growth may result in uncorrelated answers that provide 
a low repeatability coefficient, and the solution of this problem is not necessarily an increase in the number of measurements.

Assuming that gene expression can be affected not only by the stage of development but also by the different climatic conditions and changes in management to which plants are subjected over the year, the study of genotypic stabilization can contribute to improving reliability at the selection of a trait through the identification of groups of repeated measures with a higher degree of correlation.

The objective of this study was to evaluate the genotypic stabilization of agronomic traits in Panicum maximum hybrids.

\section{Material and Methods}

The experiment was conducted in the city of Campo Grande-MS, Brazil (20 $27^{\prime}$ latitude and $54^{\circ} 57^{\prime}$ longitude). According to Köppen's classification, the climate in the region is a savannah rainy tropical type, Aw subtype, characterized by an irregular annual distribution of rainfall and by the well-defined occurrence of the dry season during the cold months and rainy season during the summer. Climatic data were recorded throughout the experimental period (Figure 1).

Individual hybrids from three progenies of full siblings of $P$. maximum were evaluated. These hybrids were obtained by crossings among four potential plants - sexual mother plants S10 and S12 and apomictic cultivars Mombasa and Tanzania - which were pollen donators. Progeny 1 resulted

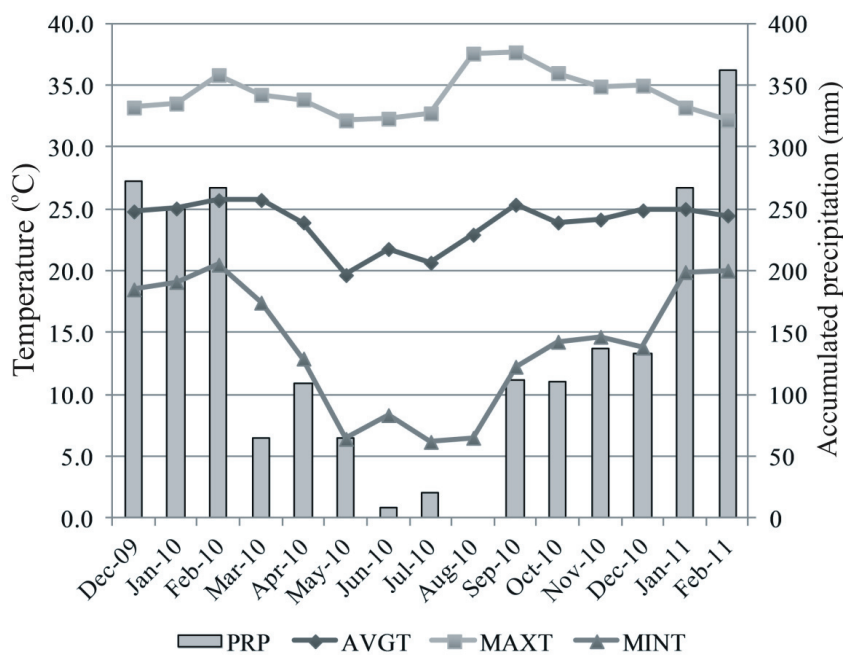

Source: metereological station of Embrapa Gado de Corte.

PRP - precipitation; AVGT - average temperature; MAXT - maximum temperature; MINT - minimum temperature.

Figure 1 - Climatic and precipitation data recorded during the experiment. from the cross between sexual plant $\mathrm{S} 10$ and Tanzania grass; progeny 2 resulted from the cross between the same sexual plant and Mombasa grass; and progeny 3 resulted from the cross between sexual parent S12 and Tanzania grass.

The seeds were obtained by polycross blocks in May and June 2007, when the polyploidized mother plants were placed amidst $25 \mathrm{~m}^{2}$ plots established with the parents to increase pollen density and reduce selfing. Seeds were germinated in December 2007 and transplanted to plastic bags in a greenhouse in February 2008, where they remained until they showed sufficient growth to be transplanted into the field, in November 2008.

The soil sampled in the experimental area $(0-20 \mathrm{~cm}$ top layer) was analyzed chemically, showing the following results: $\mathrm{pH}$ in water $(1: 2.5$ ratio $)=5.10 ; \mathrm{P}^{-M_{e h l i c h}}{ }^{-1}=$ $2.61 \mathrm{mg} / \mathrm{dm}^{3} ; \mathrm{K}^{+}=17.70 \mathrm{mg} / \mathrm{dm}^{3} ; \mathrm{Ca}^{2+}=6.56 \mathrm{cmol}_{\mathrm{c}} / \mathrm{dm}^{3} ;$ $\mathrm{Mg}^{2+}=1.62 \mathrm{cmol} / \mathrm{dm}^{3} ; \mathrm{Al}^{3+}=0.11 \mathrm{cmol}_{\mathrm{c}} / \mathrm{dm}^{3} ; \mathrm{H}+\mathrm{Al}=$ $3.01 \mathrm{cmol} / \mathrm{dm}^{3}$, base saturation $(\%)=57.17$; aluminum saturation $(\%)=2.70$; and organic matter $=3.24 \mathrm{dag} / \mathrm{kg}$. Based on the results of this analysis, during the establishment of the plots in the field, $120 \mathrm{~kg} / \mathrm{ha} \mathrm{P}_{2} \mathrm{O}_{5}$ were applied as single superphosphate. The area where the experiment was implanted was prepared by the conventional method, with plowing, application of limestone, and harrowing at the end of the rainy season before the transplantation of seedlings into the field. During the experimental period, plants received the application of $100 \mathrm{~kg} / \mathrm{ha} \mathrm{N}, 100 \mathrm{~kg} / \mathrm{ha}$ $\mathrm{K}_{2} \mathrm{O}$ and $100 \mathrm{~kg} / \mathrm{ha} \mathrm{P}_{2} \mathrm{O}_{5}$ per year. These fertilizations were made in the rainy season.

After the establishment, a total final number of 108 hybrids was obtained for progeny 1; 167 hybrids for progeny 2; and 45 hybrids for progeny 3 , totaling 320 genotypes, evaluated in an incomplete-block design. Blocks consisted of three linear plots with nine plants (tussocks), totaling 32 blocks. Each plot corresponds to one of the abovementioned progenies. Mombasa grass plants were used at the borders. The spacing between plants within a row and between rows was one meter.

The hybrid individuals were managed by harvests made at $25 \mathrm{~cm}$ above the soil level, on days $01 / 26 / 10$, 03/08/10, 06/05/10, 10/05/10, 11/18/10, 12/29/10, and $02 / 03 / 11$. The harvest made on 06/05/2010 was not assessed, as it occurred right after full flowering of the hybrids, which was the time when the seeds were also harvested for future studies. At each harvest, the forage was harvested, weighed, and subsequently sampled. In the samples, the morphological components leaf blade, stem + sheath, and dead forage were separated and later dried to determine the dry weight and their relative participation in the morphological composition of the samples. In this 
study, the following variables were considered: dry matter yield (DMY, g/plant); leaf dry matter (LDM, g/plant); stem + sheath dry matter (SDM, g/plant); percentage of leaves (\%L); and leaf:stem ratio (LSR). The $\% \mathrm{~L}$ was estimated as the division between the dry matter of leaf blades and the sum of the dry matter of leaves and stem+sheath originating from the morphological separation, i.e., it is the division between the green dry matter of leaf blades and the total green dry matter of the sample.

To estimate the coefficient of repeatability, the methods of analysis of variance (ANOVA) and principal component analysis based on the correlation matrix (PCA) were used, as described in Cruz et al. (2004).

The coefficient of repeatability by the method of analysis of variance (ANOVA) was estimated by using the statistical model with two variation factors:

$$
\mathrm{Y}_{i j}=\mu+\mathrm{g}_{i}+\mathrm{a}_{j}+\mathrm{e}_{i j}
$$

in which $\mathrm{Y}_{i j}=$ phenotypic value of the $i$-th genotype at the $j$-th measurement; $\mu=$ overall mean; $\mathrm{g}_{i}=$ random effect of the $i$-th genotype under the influence of the permanent environment; $\mathrm{a}_{j}=$ fixed effect of the temporary environment at the $j$-th measurement; and $\mathrm{e}_{i j}=$ effect of the temporary environment associated with the $j$-th measurement in the $i$-th genotype.

For this model, the coefficient of repeatability was determined as:

$$
r=\frac{\operatorname{cov}\left(Y_{i j}, Y_{i j^{\prime}}\right)}{\sqrt{V\left(Y_{i j}, Y_{i j^{\prime}}\right)}}=\frac{\hat{\sigma}_{g}^{2}}{\hat{\sigma}^{2}+\hat{\sigma}_{g}^{2}}
$$

in which $\widehat{\sigma}_{\mathrm{g}}^{2}=$ co-variance between the repeated measures in each genotype; and $\widehat{\sigma}^{2}=$ residual variance.

By the PCA method, the repeatability coefficient was estimated based on the matrix of intra-class correlations. The correlation matrix method was proposed by Abeywardena (1972) and is based on obtaining the correlation matrix between the repeated measures and subsequently estimating the normalized eigenvalues and eigenvectors. Among the estimated eigenvectors, the one with elements of the same sign and with close magnitudes is identified, as it is the eigenvector that best expresses the genotypes' trend in maintaining their relative positions in the several periods of time. The coefficient was estimated as follows:

$$
r=\frac{\hat{\lambda}_{1}-1}{\eta-1}
$$

in which $\hat{\lambda}_{1}=$ eigenvalue of the correlation matrix associated with the eigenvector whose elements have the same sign and similar magnitude; and $\eta=$ number of measures.

The genotypic stabilization of the traits was evaluated using both methods for the successive measurements, considering 2, 3, ... until all the $\mathrm{n}$ evaluations performed. Therefore, we conducted $\mathrm{n}-1$ analyses of two successive measurements, and $n-2$ analyses of three successive evaluations until six measurements were obtained (Cruz et al., 2004).

For each trait, the determination provided by the use of combinations between harvests was obtained as follows:

$$
\eta_{o}=\frac{R^{2}(1-r)}{\left(1-R^{2}\right) r}
$$

in which $\eta_{0}=$ number of measures to obtain the desired coefficient of determination $\left(\mathrm{R}^{2}\right)$; and $\mathrm{r}=$ estimated coefficient of repeatability.

All analyses were performed using the GENES computer software, in the Biometrics section (Computer Software for Genetics and Statistics) (Cruz, 2006).

\section{Results and Discussion}

The interference of the time of evaluation of the Panicum maximum hybrids on the coefficient of repeatability of the agronomic traits was studied through coefficients estimated based on the combination of groups of successive harvests. In fact, it is noted that the coefficients estimated based on groups that included evaluations performed in the dry and rainy seasons together resulted in a decrease in the coefficients of repeatability and determination of the agronomic traits (Tables 1, 2, and 3). In this sense, for all evaluated traits, the effect of inclusion of the dry-season harvests on the coefficient of repeatability was negative.

For total dry matter (TDM), the best results were obtained with the evaluation based on combinations of harvests 4, 5 and 6, which were made in the dry-rainy season transition (harvest 4), and in the rainy season (5 and 6) (Table 1). The same was not observed in the cluster of the first two harvests, which were made in the rainy season; however, the onset of harvesting management resulted in transitory growth conditions, or in the differentiated expression of genes, which may have yielded lower coefficients of repeatability, even considering two evaluations within the same season of the year. Despite this little reduction, the coefficient remained at relatively high values, especially when compared with other evaluated traits. In view of this result, the genotypic stabilization in the evaluation of plants recently established in the field, or which are going through changes in management, is notably important, because in the first harvests plants commonly show a differentiated response from the adult stage, when they are in fact capable of representing the conditions in which they will be used (Pereira et al., 2002). 
Table 1 - Estimates of coefficient of repeatability and coefficient of determination (in parenthesis) of total dry matter and leaf dry matter considering different groups of successive harvests in Panicum maximum hybrids according to the ANOVA and principal component analysis (PCA) methodologies

\begin{tabular}{|c|c|c|c|c|c|}
\hline \multirow{2}{*}{ Evaluation } & \multirow{2}{*}{$\eta$} & \multicolumn{2}{|c|}{ Total dry matter } & \multicolumn{2}{|c|}{ Leaf dry matter } \\
\hline & & ANOVA & PCA & ANOVA & PCA \\
\hline $1-2$ & 2 & $0.6894(81.61)$ & $0.7165(83.48)$ & $0.7176(83.56)$ & $0.7318(84.51)$ \\
\hline $2-3$ & 2 & $0.4018(57.33)$ & $0.6285(77.19)$ & $0.3529(52.16)$ & $0.6618(79.65)$ \\
\hline $3-4$ & 2 & $0.5913(74.32)$ & $0.7291(84.33)$ & $0.5097(67.53)$ & $0.8204(90.13)$ \\
\hline $4-5$ & 2 & $0.8179(89.98)$ & $0.8374(91.15)$ & $0.8181(90.00)$ & $0.8243(90.37)$ \\
\hline $5-6$ & 2 & $0.7697(86.98)$ & $0.7844(87.92)$ & $0.8006(88.93)$ & $0.8061(89.27)$ \\
\hline $1-3$ & 3 & 0.4959 (74.69) & $0.6265(83.42)$ & $0.4987(74.90)$ & $0.6533(84.97)$ \\
\hline $4-6$ & 3 & $0.7557(90.27)$ & $0.7912(91.92)$ & $0.7916(91.93)$ & $0.8038(92.47)$ \\
\hline $1-4$ & 4 & $0.5433(82.63)$ & $0.6679(88.95)$ & $0.5670(83.97)$ & $0.6984(90.26)$ \\
\hline $2-5$ & 4 & $0.6132(86.38)$ & $0.7022(90.41)$ & $0.6120(86.32)$ & $0.7353(91.74)$ \\
\hline $3-6$ & 4 & $0.6381(87.58)$ & $0.7220(91.22)$ & $0.6579(88.50)$ & $0.7762(93.28)$ \\
\hline $1-5$ & 5 & $0.5678(86.79)$ & $0.6723(91.12)$ & $0.5939(87.97)$ & $0.7008(92.13)$ \\
\hline $2-6$ & 5 & $0.6167(88.94)$ & $0.6928(91.85)$ & $0.6354(89.71)$ & $0.7328(93.20)$ \\
\hline
\end{tabular}

$\eta$ - number of successive harvests.

Table 2 - Estimates of coefficient of repeatability and coefficient of determination (in parenthesis) of stem dry matter and percentage of leaves considering different groups of successive harvests in Panicum maximum hybrids according to the ANOVA and principal component analysis (PCA) methodologies

\begin{tabular}{|c|c|c|c|c|c|}
\hline \multirow{2}{*}{ Evaluation } & \multirow{2}{*}{$\eta$} & \multicolumn{2}{|c|}{ Stem dry matter } & \multicolumn{2}{|c|}{ Percentage of leaves } \\
\hline & & ANOVA & PCA & ANOVA & PCA \\
\hline $1-2$ & 2 & $0.4792(64.79)$ & $0.5095(67.51)$ & $0.3123(47.59)$ & $0.3127(47.64)$ \\
\hline $2-3$ & 2 & $0.0369(7.12)$ & $0.2466(39.56)$ & $-0.0302(0.00)$ & $0.0319(6.19)$ \\
\hline $4-5$ & 2 & $0.1978(33.02)$ & $0.4221(59.37)$ & $0.2009(33.46)$ & $0.2868(44.57)$ \\
\hline $5-6$ & 2 & $0.4760(64.50)$ & $0.5197(68.40)$ & $0.4638(63.37)$ & $0.4766(64.55)$ \\
\hline $1-3$ & 3 & $0.2575(50.99)$ & $0.3733(64.12)$ & $0.0558(15.07)$ & $0.1602(36.41)$ \\
\hline $4-6$ & 3 & $0.3090(57.29)$ & $0.4477(70.86)$ & $0.2954(55.71)$ & $0.3254(59.13)$ \\
\hline $1-4$ & 4 & $0.2071(51.09)$ & $0.3468(67.98)$ & $0.0573(19.56)$ & $0.1604(43.32)$ \\
\hline $2-5$ & 4 & $0.2216(53.24)$ & $0.3493(68.22)$ & $0.0831(26.59)$ & $0.2201(53.03)$ \\
\hline $3-6$ & 4 & $0.2190(52.87)$ & $0.3459(67.90)$ & $0.0959(29.79)$ & $0.2182(52.75)$ \\
\hline $1-5$ & 5 & $0.2462(62.02)$ & $0.3645(74.14)$ & $0.1118(38.64)$ & $0.2240(59.07)$ \\
\hline $2-6$ & 5 & $0.2736(65.32)$ & $0.3763(75.11)$ & $0.1464(46.16)$ & $0.2627(64.04)$ \\
\hline
\end{tabular}

$\eta$ - number of successive harvests.

Observing the coefficient of repeatability of leaf dry matter (LDM), it can be noted that it had higher values than that of TDM, which indicates that the prediction of the genotypic value through repeated measures may provide more reliable results. In genetic breeding, LDM has been recommended, because leaves have a closer relationship with forage intake by the animals and with weight gain. Observing the clusters of harvests that provided greater repeatability, we note the same trend observed for TDM, with higher coefficients when harvests between 4 and 6 were grouped, wherein a greater repeatability was obtained with the clustering of harvests 4 and 5 (Table 1). In a similar study, Martuscello et al. (2013) obtained repeatability coefficients lower than those of this study, with 0.212 and 0.411 for TDM and LDM, respectively.

There was coincidence between the highest coefficients of repeatability and determination by the ANOVA method for TDM and LDM. For the PCA method, however, the highest coefficients of determination coincided with the clusters of greatest repeatability, but there was also an increase in the coefficient of determination in the clusters with a larger number of harvests. The clusters with a larger number of successive harvests were likely more capable of representing the variation in the data. 
Table 3 - Estimates of coefficient of repeatability and coefficient of determination (in parentheses) of the leaf:stem ratio considering different groups of successive harvests in Panicum maximum hybrids according to the ANOVA and principal component analysis (PCA) methodologies

\begin{tabular}{llcc}
\hline & & \multicolumn{2}{c}{ Leaf:stem ratio } \\
\cline { 2 - 4 } Evaluation & $\eta$ & ANOVA & PCA \\
\hline $1-2$ & 2 & $0.2187(35.89)$ & $0.2891(44.85)$ \\
$2-3$ & 2 & $0.0033(0.67)$ & $0.0729(13.59)$ \\
$3-4$ & 2 & $0.0662(12.43)$ & $0.1094(19.71)$ \\
$4-5$ & 2 & $0.1147(20.58)$ & $0.1578(27.26)$ \\
$5-6$ & 2 & $0.0125(2.47)$ & $0.2140(35.25)$ \\
$1-3$ & 3 & $0.0023(0.67)$ & $0.1564(35.74)$ \\
$2-4$ & 3 & $0.0343(9.64)$ & $0.1119(27.44)$ \\
$3-5$ & 3 & $0.0781(20.27)$ & $0.0909(23.07)$ \\
$4-6$ & 3 & $0.0588(15.79)$ & $0.1451(33.74)$ \\
$1-4$ & 4 & $0.0232(8.66)$ & $0.1396(39.36)$ \\
$2-5$ & 4 & $0.0531(18.31)$ & $0.1142(34.03)$ \\
$3-6$ & 4 & $0.0530(18.30)$ & $0.0993(30.61)$ \\
$1-5$ & 5 & $0.0400(17.25)$ & $0.1270(42.12)$ \\
$2-6$ & 5 & $0.0405(17.43)$ & $0.1247(41.60)$ \\
$1-6$ & 6 & $0.0326(16.82)$ & $0.1268(46.57)$ \\
\hline
\end{tabular}

$\eta$ - number of successive harvests.

Overall, the groups of harvests that provided the highest repeatability by the ANOVA method had similar values to those estimated by the principal component method, whereas the harvests of low repeatability and determination showed higher values by ANOVA than by the PCA method (Tables 1 to 3). According to Mansour et al. (1981), when the real value of repeatability is low, the method based on PCA tends to overestimate the coefficient. In this regard, observing the clustering of harvests 3 and 4 for LDM by PCA, an increase can be observed in repeatability, which was not recorded for LDM by the ANOVA method or for TDM by either method.

The dry matter of stems (SDM) also showed better repeatability when harvests 1 and 2; 5 and 6; and 4, 5, and 6 were considered (Table 2). For this variable, the coefficient of repeatability estimated with the data from the first and second harvests was higher than those of the other combinations. It is possible that the peculiar conditions of environment generated this result. The months in which the first and second harvests were made were characterized by the highest precipitation and temperatures of the entire experimental period (Figure 1). This fact partly explains the peculiar response of SDM during this period, which is usually higher under favorable growth conditions and with harvests made in fixed evaluation periods. In general, a higher coefficient of determination was obtained when all harvests of the experiment were considered for plants, and when combinations between 5 and 6 ; and 4,5 , and 6 were included for the plots.
The evaluation of groups of harvests was not able to provide considerable improvements in the coefficient of repeatability of the percentage of leaves $(\% \mathrm{~L})$ (Table 2$)$. This is probably due to the greater participation of leaf blades during the regrowth after flowering, which occurred from the third harvest, in the dry season. The repeatability of $\% \mathrm{~F}$ was considered low, which depended on the estimation method and on the combination of harvests. Thus, higher coefficients were recorded for the combinations between harvests 4,5 , and 6 , and for the combination between harvests 1 and 2, both in the ANOVA method and in the PCA (Table 2). All combinations involving the harvest performed in the dry season generated a low coefficient of repeatability for $\% \mathrm{~L}$, which was considered nil in the combinations of 1 to 3 , 2 to 4 , and 3 to 5 . Coefficients of repeatability out of the parameter space were also observed for this variable (Table 2 ). In this regard, the inclusion of the dry-season harvest was also very detrimental to the repeatability of $\% \mathrm{~L}$. According to Mansour et al. (1981), the ANOVA method may have negative values as long as the genotypic value is negative. Martuscello et al. (2007) observed significantly higher repeatability for the percentage of leaf blades evaluated in families of half-siblings of $P$. maximum, according to the PCA method based on the correlation matrix. According to these authors, the main factor of reduction of repeatability was the proximity to flowering, which implies excessive accumulation of stems by the forage plants.

The leaf:stem ratio (L:S) showed the lowest coefficients of repeatability, such that the use of all harvests, including the rainy and dry seasons, provided a coefficient close to zero (Table 3). As can be observed, the repeatability obtained in all harvests of the experiment was 0.0326 by ANOVA and 0.1266 by the PCA method. These results indicate that the real value of this coefficient is low and that there was no correlation between the successive measures.

Unlike the other variables, the evaluation of $\mathrm{L}: \mathrm{S}$ by repeatability coefficients was also favored by the use of the first and second harvests, whereas no other combination provided satisfactory values for the parameter in question (Table 3). In fact, the first harvests were made in the rainy season, but soon after the start of the experiment, when plants were subjected to a new defoliation management. It is possible that, after the beginning of the evaluation period, plants accumulated a large amount of stems due to the prolonged growth period that took place before the start of the evaluations. Hence, the accumulation of stem and pseudostem was exacerbated on these dates, leading to a greater correlation between the harvests.

Most studies in forage breeding in Brazil are focused on the improvement of agronomic traits such as dry 
matter yield, leaf yield, regrowth, and leaf percentage. On the other hand, forage quality has not been extensively studied, especially in the initial stages of evaluation of improved plants. This is probably due to the difficulty in evaluating characteristics as crude protein, fiber content and digestibility when they are evaluated by conventional methods. In spite of this, leaf:stem ratio may be used as an indicative of forage quality and this characteristic may easily be estimated by the ratio between the weights of leaves and stems. Therefore, it can be used as a way to improve quality in forage breeding. Few researchers have mentioned the use of leaf:stem ratio in forage breeding. This may probably be explained by the great variation observed in this characteristic because of the advancement of the phenological stages of the plants, which negatively affects forage quality and may reduce the coefficients of heritability and repeatability.

By the ANOVA method, the highest coefficients of determination coincided with evaluations 1 and 2, and 4 and 5. By PCA, however, the highest coefficient of determination was obtained with the use of all harvests and with the evaluation performed with the first and second harvests, indicating that the coefficients estimated based on these harvests can be more representative of the real value of the parameter.

In the process of estimating the coefficient of repeatability by the ANOVA method, a simpler model was used, which did not include the interaction between genotype and environment. In this case, the environment can be understood as the different harvests of the experiment. Thus, the occurrence of this type of interaction may negatively affect the estimates by the ANOVA method, and all the types of interactions will be included in the residual variation. In spite of this, during the process of estimating the coefficient of repeatability, it is only interesting to know the variations that occur in the same sense; in other words, the degree of correlation between the repeated measures. In this sense, it may be assumed that in the cases where there is great repeatability, or high correlation between the repeated measures, there will be a low interaction effect between the genotypes and harvests.

The low coefficient of repeatability can be understood as a consequence of the high residual variation, which, in situations in which the objective is to evaluate differences or rank the genotypes, may increase the residual mean square and contribute for differences between the individuals not to be perceived, implying the occurrence of type-II error. In addition to undermining the process of ranking and differentiation of genotypes, the low repeatability also indicates that the trait has low heritability, which makes it difficult to improve this trait that is so important for the forage characterization. According to Falconer and Makcay (1996), repeatability can be understood as the maximum value that the broad-sense heritability can reach.

In general, the coefficients of repeatability estimated for the rainy season were higher, and this indicates that the evaluation of forages in this period indeed has higher reliability. In this regard, Ferreira et al. (2010) evaluated the genotypic stabilizationof alfalfa during the dry and rainy seasons separately and obtained high coefficients of repeatability and determination for dry matter production in the two seasons.

The inclusion of evaluations performed in the early vegetative stage, in which the genetic potential of the studied plants is not fully manifested, or evaluations performed at advanced ages, when the materials are already under senescence, may result in a reduction of the repeatability estimate. However, according to Pereira et al. (2002), the exclusion of evaluations in two stages in which there is no genotypic stabilization may be more appropriate than increasing the number of harvests. In this sense, the exclusion of the dry-season harvest may imply a substantial increase in repeatability and greater reliability at selection of genotypes.

\section{Conclusions}

Harvests performed in the rainy season provide higher coefficients of repeatability and determination for the selection of genotypes, thus improving the genotypic stabilization during these periods.

Inclusion of the harvest performed in the dry season in the calculation of repeatability is detrimental to the process of selection of low-repeatability traits such as percentage of leaves, stem dry matter, and leaf:stem ratio.

Total dry matter and leaf dry matter show high repeatability when evaluated in groups of harvests with greater stabilization.

The dry matter of stems, percentage of leaves, and leaf:stem ratio show low repeatability in groups of harvests, indicating that the genotypes did not achieve stabilization.

\section{References}

Abeywardena, V. 1972. An application of principal component analysis in genetics. Journal of Genetics 61:27-51.

Cruz, C. D.; Regazzi, A. J. and Carneiro, P. C. S. 2004. Modelos biométricos aplicados ao melhoramento genético: v.1. 3.ed. UFV, Viçosa, MG.

Cruz, C. D. 2006. Programa Genes, Biometria. 1.ed. Editora UFV, Viçosa, MG. 
Falconer, D. S. and Makcay, T. F. C. 1996. Introduction to quantitative genetics. 4th ed. Longman, Essex.

Ferreira, R. P.; Vasconcelos, E. S.; Cruz, C. D.; Barioni Júnior, W.; Rassini, J. B.; Freitas, A. R.; Vilela, D. and Moreira, A. 2010. Determinação do coeficiente de repetibilidade e estabilização genotípica das características agronômicas avaliadas em genótipos de alfafa no ano de estabelecimento. Revista Ceres 57:642-647.

Jank, L.; Resende, R. M. S. and Valle, C. B. 2008. Melhoramento genético de Panicum maximum. p.55-87. In: Melhoramento de forrageiras tropicais. Resende, R. M. S.; Valle, C. B. and Jank, L., eds. Embrapa, Campo Grande.

Jank, L.; Valle, C. B. and Resende, R. M. S. 2011. Breeding tropical forages. Crop Breeding and Applied Biotechnology (Special edition 1):27-34.

Pereira, A. V.; Cruz, C. D.; Ferreira, R. P.; Botrel, M. A. and Oliveira, J. S. 2002. Influência da estabilização de genótipos de capim elefante (Pennisetum purpureum Schum.) sobre a estimativa da repetibilidade de características forrageiras. Ciência e Agrotecnologia 26:762-767.

Mansour, H.; Nordheim, E. V. and Rutledge, J. J. 1981. Estimators of repeatability. Theoretical and Applied Genetics 60:151-156.

Martuscello, J. A.; Jank, L.; Fonseca, D. M.; Cruz, C. D. and Cunha, D. N. F. V. 2007. Repetibilidade de caracteres agronômicos em Panicum maximum Jacq. Revista Brasileira de Zootecnia 36:1975-1981.

Martuscello, J. A.; Braz, T. G. S.; Jank, L.; Cunha, D. N. F. V.; Souza, M. W. M.; Brito, G. F. and Oliveira, L. P. 2013. Repeatability of agronomic characters in Brachiaria brizantha cultivars. Revista Brasileira de Zootecnia 42:30-35.

Valle, C. B.; Jank, L. and Resende, R. M. S. 2009. O melhoramento de forrageiras tropicais no Brasil. Revista Ceres 56:460-472. 